Revue d'histoire de l'Amérique française

Q8. REVUE D'HISTOIRE DE L'AMÉRIQUE FRANÇAISE

\title{
In memoriam : Andrée Désilets (1928-2017)
}

\section{Guy Laperrière}

Volume 71, numéro 1-2, été-automne 2017

URI : https://id.erudit.org/iderudit/1042783ar

DOI : https://doi.org/10.7202/1042783ar

Aller au sommaire du numéro

Éditeur(s)

Institut d'histoire de l'Amérique française

ISSN

0035-2357 (imprimé)

1492-1383 (numérique)

Découvrir la revue

Citer ce document

Laperrière, G. (2017). In memoriam : Andrée Désilets (1928-2017). Revue

d'histoire de l'Amérique française, 71(1-2), 5-6. https://doi.org/10.7202/1042783ar d'utilisation que vous pouvez consulter en ligne.

https://apropos.erudit.org/fr/usagers/politique-dutilisation/ 


\section{In memoriam Andrée Désilets (I928-20I7)}

C est avec beaucoup de peine que la communauté historienne a appris le décès d'Andrée Désilets, survenu le 9 mai 2017.

Native de Sherbrooke, Andrée Désilets complète ses études supérieures en histoire à l'Université Laval, avec Jean Hamelin, auquel elle est restée très attachée et avec qui elle a rédigé une thèse de doctorat remarquée sur Hector-Louis Langevin, un Père de la Confédération canadienne (18261906), thèse soutenue en 1967. Les deux

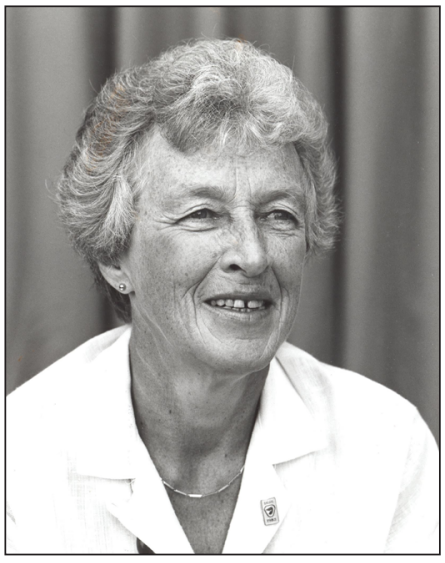
années suivantes, elle enseigne à Gaspé, au cégep de la Gaspésie, région qui l’a fascinée. Elle est ensuite engagée au Département d'histoire de l'Université de Sherbrooke, où elle sera professeure pendant vingt ans (1970-1990). Elle y a assurément laissé sa marque. Première directrice de département de l'université, elle sait stimuler les étudiants, particulièrement ceux de maîtrise. Elle lance la collection «Histoire des Cantons de l'Est», qui publie plusieurs de leurs mémoires.

Sa spécialité est la biographie historique, dont elle fait le thème de son discours de réception à la Société Royale du Canada, en 1982. Collaboratrice assidue du Dictionnaire biographique du Canada, elle y produit quelque 45 biographies, réparties des volumes III (1741-1770) à XIV (19111920); on me dit même qu'il en paraîtra une dans le volume XVI. Ce sont principalement des hommes politiques québécois du XIX ${ }^{e}$ siècle, dont elle 
avait fait sa spécialité, les Taché, Lemieux, Cauchon, Chapais, Mousseau, Sicotte, Chapleau, Masson, Langelier, mais aussi un plus grand nombre de religieuses dont plusieurs fondatrices bien connues, Rosalie Cadron, Marcelle Mallet, Marie Fisbach. En outre, elle produit en 1985 une élégante biographie de Louis-Rodrigue Masson, un seigneur sans titres.

À Sherbrooke, elle a été une bougie d'allumage pour l'histoire régionale, donnant à l'antique Société d'histoire des Cantons de l'Est une nouvelle vie, la transformant en Société d'histoire de Sherbrooke et la faisant loger dans un bel édifice patrimonial, rue Dufferin. Présidente de cette société de 1981 à 1992, elle multiplie les instruments de diffusion de l'histoire et lance la Société sur un élan qui l'inspire encore aujourd'hui.

Il convient de souligner surtout ici son travail comme secrétaire de rédaction, puis directrice, de la Revue d'histoire de l'Amérique française, de 1978 à 1985, puis comme présidente de l'Institut d'histoire de l'Amérique française de 1985 à 1989. Elle y était très attachée et avait à cœur la haute tenue de la revue. Elle était aimée de tout le monde et savait gagner la confiance de ses collaborateurs. Discrète sur elle-même, elle suscitait vocations et collaborations. On n'en finirait plus d'énumérer les lieux et les organismes où elle s'est engagée, Société canadienne d'histoire de l'Église catholique, Société historique du Canada, Commission des lieux et monuments historiques du Canada, Commission de toponymie du Québec. Là où elle était, elle s'engageait à fond, témoin cet historique de L'Académie des lettres et des sciences humaines de la Société royale du Canada qu'elle publie en 1987. Toute cette activité est couronnée par un doctorat d’honneur de l’Université Bishop's en 1992.

C'était une historienne accomplie, passionnée de l'histoire bien faite et bien écrite, qui a porté très haut le flambeau de notre discipline et l'amour de ses étudiants, qui le lui rendaient bien. Son nom restera dans nos mémoires.

Guy Laperrière Université de Sherbrooke 